\title{
IMMERSIVE INTERCULTURAL EXPERIENCE FOR GRAPHIC COMMUNICATION STUDIES THROUGH VIRTUAL REALITY
}

\author{
Mohd Asrizal Razali ${ }^{1}$, Noranis Ismail ${ }^{1}$, Nurzihan Hassim ${ }^{2}$ \\ ${ }^{1}$ Taylors University, Faculty of Innovation \& Technology, The Design School, \\ Subang Jaya, Malaysia \\ ${ }^{2}$ Taylors University, Faculty of Social Sciences and Leisure Management, School of Media and \\ Communication, Subang Jaya Malaysia
}

\begin{abstract}
At Taylor's University, Intercultural Design is a project-based module where students are exposed to different cultures of foreign countries and are required to understand the role of design in a wide cultural, political and social context. Through this experience in addition to reflective practice, conceptualizing of ideas and active experimentations, the participating graphic communication students interpret their immersion of culture subjectively and present a piece that communicates the said cultural elements to intended audiences. The present COVID-19 international travel restrictions had disrupted this knowledge acquisition process and posed limits of onsite exploration, engagement with foreign agencies and face-to-face interactions with communities and cultures. However, previous studies had posited the potential of utilizing similar approaches via virtual space, place metaphors and avatar-environment interaction. Henceforth, this paper explored Virtual Reality (VR) technology that replicated environments of foreign destinations and allowed students to map information from this perspective in order to produce a graphic design-based output. This paper intended to further examine the effectiveness of VR by comparing information and feedback of; 1)participating students who had firsthand experience of foreign environment, and 2) students who only have second hand experience via VR. This paper also proposed the suitable selection of VR tools based on cost, accessibility, technological requirements and immersion satisfaction via online learning. The results achieved during the analysis is pertinent to endorse the intention towards the use of $V R$ tools for online collaborative and student-centered learning experience for this module.
\end{abstract}

Key words: Intercultural design, virtual reality, experiential learning, immersive experience, graphic design

\section{INTRODUCTION}

The COVID-19 pandemic has challenged the norms of teaching and learning in the education sector. With its key focus on four factors; globalization, teaching and learning, governance and knowledge-based society (Grapragasem et al, 2014), the Malaysian higher education landscape was severely affected with the implementation of a strict Movement Control Order (MCO) in March 2020 with the attempt to break the chain of the virus and to flatten the pandemic curve. Academic institutions had little option but to deploy a crisis strategy to safeguard their biggest stakeholders - the students; and also to ensure smooth delivery of classes with the implementation of online learning.

Intercultural Design is a module offered by The Design School (TDS) at Taylors University, Malaysia and the class delivery is affected by the pandemic situation as nations are forced to close their borders and limit travelers. As this module focuses on experiential learning, collaborative and student-centered learning, students were encouraged to take the opportunity to understand the role of design and designers outside of their locality which demands them to look beyond the familiar setting and into a wider cultural, political and social context. The aim is to introduce students to local and global design issues and impact through active engagements with foreign agencies, face-to-face interactions with communities and cultures, which in return, may present opportunities for further collaboration. But with imposed international travel restrictions, it has disrupted the familiar knowledge acquisition process for this module through on-site exploration and aforementioned engagements. Furthermore, there is evidence that experiential learning is equally crucial to the learner's progress and takes place when; i) a person is involved in an activity, ii) he or she looks back and evaluates it, iii) determines what was useful or important to remember, iv) and uses this information to perform another activity (Kolb, 2014; Razali et al, 2018). Chavan (2011) summed experiential learning as direct encounters with the phenomena being studied rather than thinking or considering the possibility of doing something about it. Schwartz (2012) added that students hold much of the responsibility in the learning process whereby they manage their 
own learning, rather than being told what to do and when to do it. New skills, new attitudes, or new ways of thinking are also developed through experiential education where it immerses learners in an experience and then encourages reflection about the experience (Lewis and Williams, 1994).

Throughout the higher education landscape, virtual collaborative learning is implemented in a wide ranging proposition (Kopp et al, 2011). Lou (2017) mentioned three-dimensional space presentation has made design feel real and lifelike. The teaching and learning process in institutes of higher learning are constantly aided by latest technologies with systems that provide support for the practices (Chan et al, 2019). With the pandemic not showing any sign of ease, alternative methods for collaborative and student centered learning via online tools and VR devices have to be explored and implemented in an attempt to replicate environments of foreign destinations and allow students to interpret information from this secondary perspective in order to produce a graphic design based output. Jerald (2016) described VR as a user-centered technology that lends understanding towards the basis of communication. With advancement of the latest technologies, Gandhi and Patel (2018) summarized that presence in any place in the world could be mimicked vividly with VR combination of peripherals and softwares that enable users to immerse themselves into the action at the predetermined scene from the comfort of their own homes.

\subsection{Problem Statement}

As the possible COVID-19 vaccine is still in development, scientists and governments are already looking at the drastic need for a lifestyle change of the "New Normal" on a global scale in order to control the pandemic situation which includes limitation of international travels possibly for the next few years. Unfortunately, this will heavily affect the module delivery for Intercultural Design by Taylor's Design School (TDS) and requires exploring alternative methods for collaborative and student-centered learning via online tools and VR devices. The aim is to replicate environments of foreign destinations by allowing students to interpret information from the secondary VR perspective in order to produce a graphic design-based outcome from the experience.

With that said, this paper serves as a foundation study for the delivery of Intercultural Design class in January 2021 with the adoption of VR technology to replace the typical week-long excursion to a different country. We inspected the already available VR tools to access environment simulations with the use of virtual space, place metaphors and avatar-environment interaction and provide the framework to measure the immersion quality of each tool in order to determine the quality of information from a secondary VR perspective in comparison to the first-hand on-site experiences of students from the previous semesters.

\section{METHODS}

The data collected upon the completion of the semester will be analyzed with Atlas.ti CAQDAS software. As this study is to determine the immersive experience of VR tools to gather information from a secondary perspective, the basis of the data collection will be based on the reflective practices of feeling, watching, thinking and doing for each of Kolb (2014) Learning Style Index cycles of concrete experience, reflective observation, abstract conceptualization and active experimentation. The data will be utilized during the compilation of students' reflective reports for Intercultural Design January 2021 session.

We limited the selection of VR technology based on the student's capacity to access and operate the tools to gain immersive experience. The data will then be simultaneously coded to ascertain patterns based on Kolb (2005) Learning Style Index of 1) doing , 2) feeling, 3) thinking; and 4) watching.

As recommended by McClelland et al. (2008) and Schreier (2012), any emergent themes that were present during the analysis of the reflective reports will be included as subcategories to the root coding to the main categories. The data analysis and reporting will be done based on the logical flow of issues, particularly whether the VR experience participated by the learners to gather secondary perspective on information that provided immersive experience compared to the original learning excursion experience. The study constructed an inductive and thematic structure to narrate the findings from a macro level and later broke down the findings into larger meanings to identify the constructs built by learners in shaping their attitudes and behaviours towards exploring a location via VR. Select quotations were featured for each category and its subcategories to illustrate the significance themes presented. 


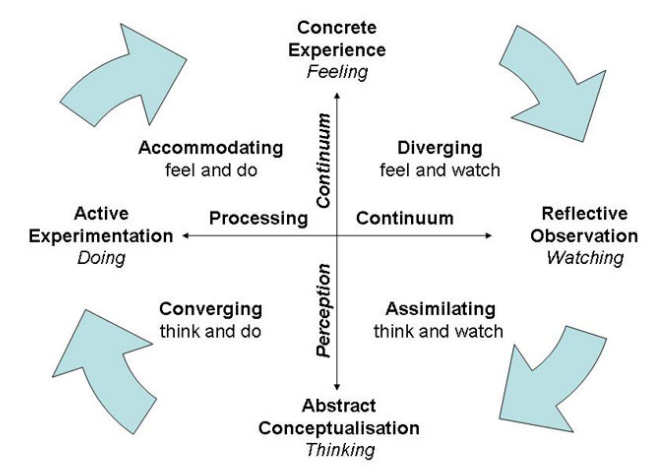

Figure 1: McLeod (2017) Summary of Kolb's Learning Style Index (LSI) through a process continuum

\section{DISCUSSION}

In the previous Intercultural Design excursion to Berlin in 2016, Razali et al (2018) analyzed the students' reflective observations as a consistent behavioural set to Kolb and Kolb (2005) Learning Style Index of 1) doing, 2) feeling, 3) thinking; and 4) thinking. While their emotions are influential, the experience of being there allowed them to identify the differences in design and local culture based on their existing knowledge of other cultures. In applying these elements, they observe and proceed to form new knowledge during the week-long trip. Although this proves to be the greater advantage to experiencing a foreign environment, but with the current pandemic situation, it is impossible to conduct the class excursion without the risk of contracting COVID-19. Therefore, an alternative experience of "being there" on-site would need to be adapted with the use of VR with hope that it would suffice in giving the students a similar experience of the tour and learning in a foreign environment as reflected in their written reports and artworks produced after.

However, due to the nature of the online class delivery where the students are required to operate the VR tools by themselves, we limited the selection of VR technology based on the account of the student's capacity to operate the equipment by themselves which means the tools and applications must be easily and readily accessible, cost free with minimum technology requirements, and provided ease of use, and immersive experience with their already available devices at home as per the following:

\subsection{Google Street View}

Ever since Google Street View was launched in 2007, it has since expanded to include cities and rural areas worldwide. This technology can be accessed for free on all devices via Google Maps by dropping the avatar Pegman; or commonly known as the Yellow Man; onto the roads on the map that are marked with blue lines and navigating the streets with the mouse. The application displays panoramas of stitched spherical images of street-level views. These images provide a complete 360-degree view of the scenery in the ground plane and 180-degree view vertically (Fernández et al, 2016) and may be able to provide a robust immersive experience for the user as they are free to navigate the scenes and revisit the old panorama images from the Street View's archives by adjusting the desired Time.

\subsection{Google Earth VR}

Released in 2017 as an extension of Google Maps, Google Earth VR (GEVR) allows users to visit the world's cities, landmarks and natural wonders with the use of VR equipment such as Oculus Rift and HTC Vive from the comfort of their home. The technology aimed to get the whole world within reach using VR by relying on sensors that track a user's position and gestures in actual space. The aim here is to immerse the user with experience of virtual earth in the same way that they experience a real one: as a world they actively embody rather than a representation they examine from the outside (Belisle, 2020). On top of that, users are able to explore the panoramas from fantastic impossible perspectives like flying, standing at the top of the highest peaks and even soar into space. It also comes with cinematic tours and handpicked destinations which allow a more relaxed exploration. 


\subsection{YouTube VR Videos}

YouTube VR is a new type of online tool that offers viewers experience in exploring a video in 360degrees with their mouse or mobile devices. This medium is called spherical video under two popular categories which are "360-degree video" (360) and VR. Like GEVR, as explained by YouTube Creators (2016) website, the YouTube VR can even be viewed in a head-mounted display and gives an immersive experience of exploring the surroundings in all directions, interacting with and experiencing the content instead of passively watching a video. With the recent COVID-19 pandemic, many YouTube content creators are producing more and more VR walkabout videos. This caters to the viewers desire of exploring the outside world from this medium and giving them the feeling of "being there". With the increase of such activities, viewers are also able to view the latest panorama or scenes of specific locations via YouTube VR such as the Japan Travel Sensei (2020) YouTube channel which produces 360degree VR videos of hot spots in Tokyo.

\section{CONCLUSIONS}

In order to transition into the workforce, one of the necessary skills required to help universities stay relevant to the students is through experiential learning (Cantor, 1995). Even with the challenges of adapting online learning, technology advancement may provide respite in easing the transition of class delivery for Intercultural Design with the use of VR tools. By allowing students some levels of sensory experience, VR may have the capacity to allow immersive experience in cultural studies. Heeter (1992), Shim and Kim (2003) in Teng (2010), mentioned that immersion, presence or telepresence refers to the strength of a user's sense of "being there". However, the quality of the immersive experience may refer to the extent to which a user is satisfied with such a feeling (Teng, 2010). This means immersive quality can be a weak feeling of "being there" while others may require a more concrete experience rather than just second hand observation in VR.

\section{REFERENCES}

[1] Belisle, B.: "Whole world within reach: Google Earth VR", Journal of Visual Culture 19 (1), 112-134, 2020. doi: 10.1177/1470412920909990.

[2] Cantor, J.-A.: "Experiential learning in higher education", (ERIC Publications, Washington D.C., 1995.)

[3] Chan, S.-C.-H., Johnny Wan C.-L., Ko S.: "Interactivity, active collaboration learning, and learning performance: The moderating role of perceived fun by using personal response systems", The International Journal of Management Education 17, 94-102, 2019. doi: 10.1016/j.ijme.2018.12.004.

[4] Chavan, M.: "Higher education students' attitudes towards experiential learning in international business", Journal of Teaching in International Business 22 (2), 126-143, 2011. doi: 10.1080/08975930.2011.615677.

[5] Fernández, L.-P., Reinoso, O., Jiménez, L. M., Ballesta, M.: "A study of visual descriptors for outdoor navigation using Google street view images", Journal of Sensors 2016, 2016. doi: 10.1155/2016/1537891.

[6] Gandhi, R.-D., Patel D.-S.: "Virtual reality - Opportunities and challenges", International Research Journal of Engineering and Technology 5 (1), 482-490, 2018.

[7] Grapragasem, S., Krishnan A., Mansor A.-N.: "Current trends in Malaysian higher education and the effect on education policy and practice: An overview", International Journal of Higher Education 3 (1), 85-93, 2014. doi: 10.5430/ijhe.v3n1p85.

[8] Japan Travel Sensei: "Yanaka Ginza Shopping Street", URL: https://www.youtube.com/channel/UCrFI4j1uXJIMrmNDCNgXUcw (last request: 2020-09-27), 2020

[9] Jerald, J.: "The VR Book", (Association for Computing Machinery and Morgan \& Claypool, New York NY, 2016.)

[10] Kolb, D.-A.: "Experiential Learning: Experience as the Source of Learning and Development (Second Edition)", (Pearson Education, Upper Saddle River NJ, 2014.)

[11] Kolb, A.-Y.: "The Kolb Learning Style Inventory-version 3.12005 technical specifications", (Hay Resource Direct, Boston MA, 2005.), page 72.

[12] Kolb, A.-Y., Kolb D.-A.: "Learning styles and learning spaces: Enhancing experiential learning in higher education", Academy of Management Learning and Education 4 (2), 193-212, 2005. 
[13] Kopp, B., Matteucci M.-C., Tomasetto C.: "E-tutorial support for collaborative online learning: An explorative study on experienced and inexperienced e-tutors", Computers \& Education 58, 12-20, 2011. doi: 10.1016/j.compedu.2011.08.019.

[14] Lewis, L.-H., Williams, C.-J.: "Experiential Learning: A New Approach", (Jossey Bass, San Francisco CA, 1994.)

[15] Lou, M.: "A virtual reality teaching system for graphic design course", International Journal of Emerging Technologies in Learning 12 (9), 117-129, 2017.

[16] McLeod, S.-A.: "Kolb - Learning Styles", URL: www.simplypsychology.org/learning-kolb.html (last request: 2020-09-26), 2017.

[17] Razali, M.-A., Ismail N., Hassim N.: "The role of experiential learning in creative design appreciation among TDS students at Taylor's University", Advances in Social Science, Education and Humanities Research 207, 203-208, 2018.

[18] Schreier, M.: "Qualitative Content Analysis in Practice", (Sage Publications, Thousand Oaks CA, 2012.)

[19] Schwartz, M.: "Best practices in experiential learning: An expanded definition", Ryerson University, 1-18, 2012.

[20] Teng, C.-I.: "Customization, immersion satisfaction, and online gamer loyalty", Computers in Human Behavior 26 (6), 1547-1554, 2010. doi: 10.1016/j.chb.2010.05.029.

[21] YouTube Creators: "Introduction to 360-degree video and virtual reality", URL: https://creatoracademy.youtube.com/page/course/360video (last request: 2020-09-24), 2016.

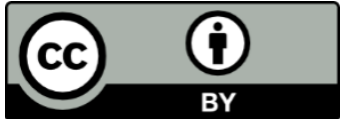

(C) 2020 Authors. Published by the University of Novi Sad, Faculty of Technical Sciences, Department of Graphic Engineering and Design. This article is an open access article distributed under the terms and conditions of the Creative Commons Attribution license 3.0 Serbia (http://creativecommons.org/licenses/by/3.0/rs/). 